\title{
PerCursos
}

\section{Entre mundos: a colonialidade no rompimento da barragem de fundão em Mariana/MG. Sentidos e percepções dos Krenak}

\section{Resumo}

O rompimento da barragem de rejeitos de Fundão, no município de Mariana/Minas Gerais, em novembro de 2015, contaminou o rio Doce e atingiu drasticamente o povo Krenak, que vive às margens desse rio. Este trabalho propõe a análise dos depoimentos publicados por lideranças e intelectuais Krenak a respeito do rompimento da barragem, através das discussões sobre modernidade e colonialidade desenvolvidas por autores do pensamento decolonial latino-americano. A metodologia utilizada é de cunho qualitativo, com aporte na análise bibliográfica e com elementos da análise de conteúdo (BARDIN, 2016), sendo o recorte temporal os anos de 2015 a 2020. A análise demonstrou a construção das narrativas pelos Krenak sobre o desastre, não como um fato isolado, mas como mais uma violência dentro do histórico de violações de direitos a que foram submetidos desde o início da colonização e que persiste nos dias atuais. Os sentidos e percepções do povo Krenak convergem para uma crítica profunda ao modo de produção capitalista, à narrativa colonial, à visão da natureza como recurso e à crise dos valores éticos. Entre mundos antagônicos, o pensamento indígena Krenak converge com os elementos e categorias do movimento decolonial para a possibilidade de outro modo de viver.

Palavras-chave: Índios Krenak. Impacto Ambiental. Civilização moderna. Indígenas.
Roberta Brangioni Fontes

Doutoranda em

Desenvolvimento Social na

Universidade Estadual de Montes

Claros - UNIMONTES- MG. Mestre

em Extensão Rural pela Univ.

Federal de Viçosa - UFV.

Brasil

betabrangioni@yahoo.com.br

\section{Andréa Maria Narciso Rocha de Paula \\ Doutora em Geografia pela \\ Universidade Federal de \\ Uberlândia - UFU. Professora da \\ Universidade Estadual de Montes \\ Claros - UNIMONTES- MG. \\ Brasil \\ andreasertao@gmail.com}

\section{Para citar este artigo:}

FONTES, Roberta Brangioni; DE PAULA, Andréa Maria Narciso Rocha. Entre mundos: a colonialidade no rompimento da barragem de fundão em Mariana/MG. Sentidos e percepções dos Krenak. PerCursos, Florianópolis, v. 22, n.48, p. 233 - 260, jan./abr. 2021. 


\title{
Between worlds: the coloniality in the rupture of the fundão dam in Mariana/MG. Senses and perceptions of the Krenak
}

\begin{abstract}
The Fundão/Samarco tailings dam collapse in Mariana/Minas Gerais in November 2015 contaminated the Doce River and drastically affected the Krenak people who live on this riverbank. This study proposes an analysis of the published testimonies of Krenak leaders and intellectuals regarding the dam collapse through the discussions on modernity and coloniality developed by authors of Latin American decolonial thought. The methodology we used is qualitative, based on bibliographic analysis and with content analysis elements (BARDIN, 2016), and the time frame is from 2015 to 2020. The analysis demonstrated the Krenak's narrative construction on the disaster, not as an isolated fact, but as one more violence within the history of rights violations to which they have been submitted since the beginning of the colonization and which endures today. The Krenak people's meanings and perceptions converge into a severe criticism towards the capitalist production mode, the colonial narrative, the view of nature as a resource, and the ethical values crisis. Amid antagonistic worlds, the Krenak indigenous thought converges with the decolonial movement's elements and categories towards the possibility of another way of living.
\end{abstract}

Keywords: Krenak Indians. Environmental impact. Modern civilization. Indigenous peoples. 


\section{Introdução, objetivos e metodologia}

A Terra Indígena Krenak, localizada na cidade de Resplendor, à margem direita do rio Doce, em Minas Gerais (Figura 1), foi uma das comunidades atingidas pelo rompimento da barragem de rejeitos das mineradoras Samarco Mineração S.A., Vale S.A. e BHP Billiton Brasil Ltda., conhecida como Barragem de Fundão, localizada no distrito de Bento Rodrigues, a $35 \mathrm{~km}$ do município de Mariana/MG. O rompimento, ocorrido em 5 de novembro de 2015, resultou em mortes, destruição e contaminação ao longo de todo o rio Doce, da nascente à foz, afetando tragicamente a vida do povo Krenak (MILANEZ; LOSEKANN, 2016).

Este artigo tem como objetivo, à luz das discussões sobre modernidade e colonialidade, analisar os depoimentos publicados pelas lideranças e intelectuais Krenak a respeito do rompimento da barragem de rejeitos de Fundão, a partir da perspectiva indígena, das categorias de sua língua originária, sua história e cosmologia². As narrativas expressam percepções do povo Krenak sobre seu viver antes do rompimento e destacam as consequências após o rompimento e devastação do rio, o qual reverenciam como Watu.

\footnotetext{
1 Este artigo está baseado em pesquisa bibliográfica sobre o tema, para a construção de projeto de doutoramento e conta com o financiamento da Coordenação de Aperfeiçoamento de Pessoal de Nível Superior - CAPES.
} 
Figura 01 - Localização da Terra Indígena Krenak
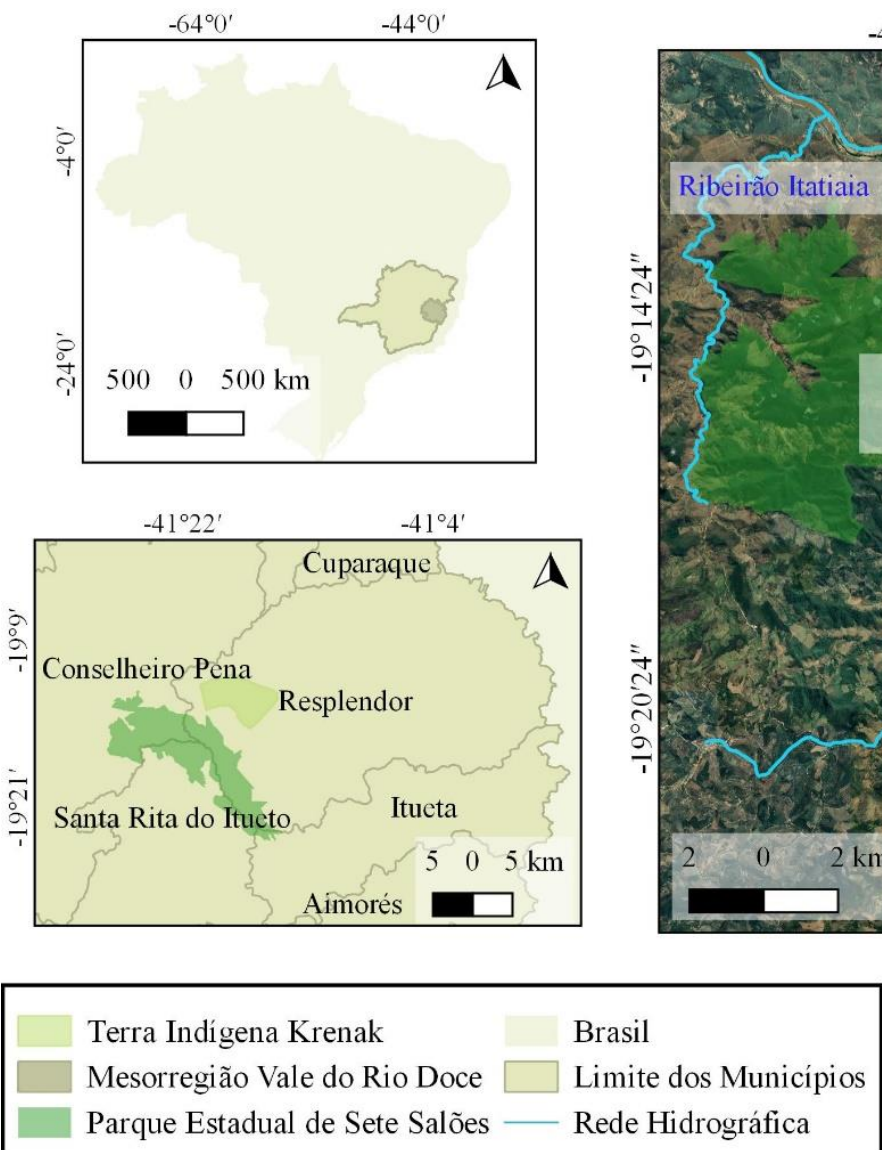

$-41^{\circ} 24^{\prime} 0^{\prime \prime}$

$-41^{\circ} 18^{\prime} 0^{\prime \prime}$

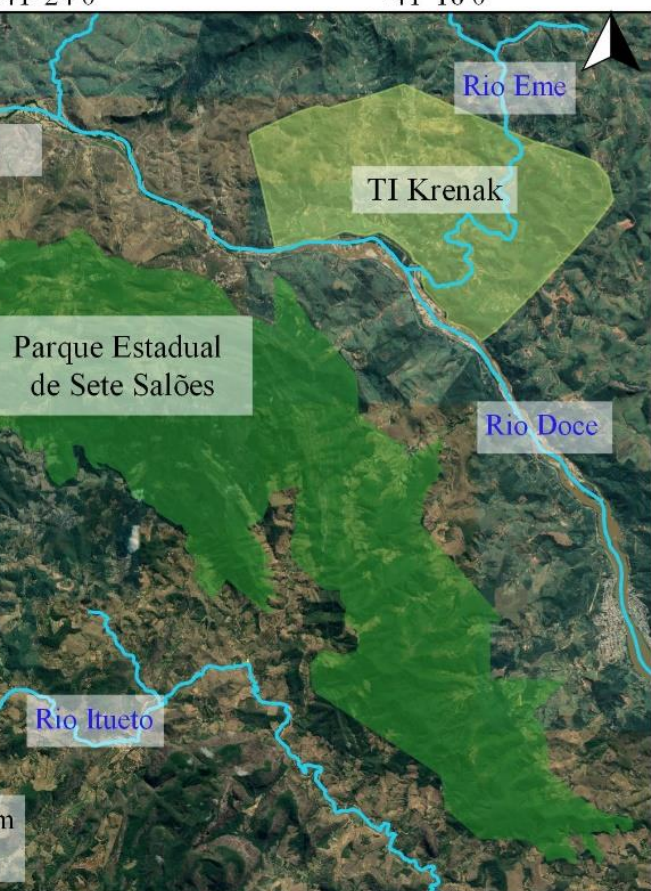

Terra Indigena Krenak

Mesorregião Vale do Rio Doce

Parque Estadual de Sete Salões
Limite dos Municípios Rede Hidrográfica
Sistema de Coordenadas Geográfica - WGS84 Fonte: IBGE, IGAM, Google Earth (Adaptado)

Fonte: Elaborado pela autora, 2021.

A abordagem metodológica, de cunho qualitativo, foi baseada na revisão bibliográfica, na interpretação de dados secundários construídos a partir do método da História $\mathrm{Oral}^{2}$ e em elementos da análise de conteúdo. A revisão bibliográfica fundamentou-se em autores latino-americanos e na reflexão das categorias epistemológicas de desenvolvimento, colonialidade e decolonialidade. A análise de conteúdo foi utilizada, ainda que de forma introdutória, no estudo dos depoimentos dos Krenak já publicados em material audiovisual, livros e dissertações.

\footnotetext{
${ }^{2} \mathrm{O}$ estudo deste artigo foi elaborado a partir da análise das narrativas já publicadas, as quais foram construídas oralmente, por isso, a História Oral é metodologia fundamental na perspectiva qualitativa utilizada (PEREIRA DE QUEIROZ, 1988).
} 
O material audiovisual analisado foi produzido a partir de lives (apresentações em ambiente remoto, na internet, em virtude do momento pandêmico que vivemos) realizadas nos meses de maio, junho e julho de 2020, como parte do projeto "Pluriversidade dos povos e comunidades tradicionais do Watu, educação intercultural e bem-viver no vale do rio Doce". O projeto é coordenado pelo professor Reinaldo Duque, em parceria com Instituto Shirley Djukurnã Krenak, do Núcleo de Agroecologia de Governador Valadares e Centro de Referência em Direitos Humanos, da UFJF/GV3.

Compreendemos que o processo de leitura "envolve mente e olhos, um processo de abstração [...]" (CALVINO, 2005, p. 145). Portanto, o estudo e a interpretação da leitura realizada de obras acadêmicas e narrativas indígenas, são o aporte para a compreensão significativa do desastre através daqueles que mais foram afetados: os povos que habitam os lugares de vida nas margens do rio.

A análise de conteúdo, como defende Bardin (2016), parte do exercício de estabelecer um olhar rigoroso sobre os dados e discernir o que existe nas entrelinhas. A técnica auxilia a interpretação, através da compreensão "do tipo de fala a que se dedica a interpretação que se pretende como objetivo" (BARDIN, 2016, p. 36-37).

Tal análise é um processo organizado em diversas fases, que busca compreender criticamente o sentido das comunicações. Neste trabalho, a análise de conteúdo foi realizada a partir do acompanhamento das lives; da transcrição dos depoimentos indígenas; da sistematização dos temas mais recorrentes nos materiais audiovisuais e nos provenientes de fonte escrita; e da análise relacionada a categorias teóricas do pensamento decolonial.

O estudo dos depoimentos demonstrou que os Krenak constroem suas narrativas sobre o desastre, não como um fato isolado, mas como mais uma violência ao seu povo, dentro do histórico de violações de direitos a que foram submetidos desde o início da colonização e que se perpetua nas diversas faces assumidas pelo modelo de sociedade

\footnotetext{
3 Em função da pandemia mundial de COVID-19, que exigiu medidas de isolamento social, as transmissões ao vivo foram uma forma de prosseguir com os diálogos de educação intercultural do projeto citado. As transcrições das lives, realizadas pela autora deste artigo, ocorreram de agosto a outubro de 2020 e as gravações originais estão disponíveis no Canal do YouTube: "Nagô UFJF-GV" <https://www.youtube.com/watch?v=M2DYt7BB_s4\&t=2218s>. Acesso em: 27 fev. 2020.
} 
ocidental moderna-colonial. Nesse sentido, a partir da perspectiva indígena, as narrativas permitem uma outra dimensão da compreensão desse desastre, destacando os danos profundos e irreparáveis que atingem várias esferas do modo de vida Krenak.

As narrativas protagonizadas por lideranças que transitam entre as esferas da vida indígena local, acadêmica e política, sobre o rompimento da barragem, revelam o viver entre mundos de concepções antagônicas, apontam uma crítica profunda ao modelo de desenvolvimento vivenciado e apresentam outras possibilidades de modos de vida.

\section{Inspirações teóricas e perspectiva epistêmica}

A perspectiva epistêmica para este trabalho compreende a colonialidade como um dos fundamentos da modernidade, na forma como tal ideia vem sendo construída há algumas décadas pelos teóricos do pensamento decolonial. Esse pensamento, como uma expressão da teoria crítica latino-americana, emerge nos anos 1990, a partir do grupo de estudos Modernidade-Colonialidade (MC - como iremos nos referir ao grupo no texto), que, originalmente, reunia pesquisadores da América Latina e dos Estados Unidos, dentre os quais podemos citar: Enrique Dussel, Aníbal Quijano, Arturo Escobar e Walter Mignolo4 (ESCOBAR, 2003).

A genealogia do grupo remete a diversas influências, dentre elas: a teologia e a filosofia da libertação; a teoria da dependência; a investigação-ação-participativa; os debates sobre uma ciência social latino-americana autônoma, sobre modernidade e pósmodernidade; estudos culturais e estudos subalternos. O programa de estudos $M C$ apresenta uma possibilidade de outra forma de pensamento epistêmico, o qual é apoiado principalmente em pesquisas sobre a realidade cultural e política latino-americana, incluindo o conhecimento historicamente invisibilizado dos grupos oprimidos (ESCOBAR, 2003).

\footnotetext{
4 Aníbal Quijano tem se dedicado mais profundamente à economia política; enquanto Dussel, à filosofia da libertação; e Mignolo à literatura e epistemologia. Escobar destaca, que para todos eles, o marxismo e a questão econômica continuam sendo temas fundamentais (ESCOBAR, 2003). Cabe também destacar a influência seminal de Immanuell Wallerstein.
} 
Uma das peculiaridades da análise sobre a modernidade, trazida pelos teóricos do MC, é o entendimento do ano de 1492, o marco do início da colonização, como momento fundante da modernidade. Para Escobar (2003, p. 60), essa é uma “énfasis en localizar los orígenes de la modernidad en la Conquista de América y el control del Atlántico después de 1492, antes que los más comúnmente aceptados mojones como la llustración o el final del siglo XVIII". Isso porque o ouro e a prata das colônias subsidiaram a origem do sistema capitalista e o próprio surgimento do conceito de modernidade.

A classificação do mundo em raças hierarquizadas, segundo a qual a raça branca e a cultura europeia estavam no ápice da evolução, foi fundamental para que, junto com a dominação econômica e política sobre as colônias, o eurocentrismo se impusesse como forma de pensamento universal, subalternizando outras culturas e outras formas de conhecimento. Dentro dessa perspectiva, a colonialidade é entendida como a persistência da relação colonial, que, apesar de ter se extinguido formalmente com a independência dos países colonizados, perpetua-se em sua dimensão cultural, na medida em que implica uma dominação imposta sobre as outras culturas e, inclusive, sobre seus imaginários. Sob a forma do eurocentrismo, muitos conhecimentos próprios dos povos colonizados (sistemas de saberes indígenas, negros e de outras etnias) foram excluídos, silenciados, subjugados e ignorados, sob a argumentação de base iluminista de que representavam uma etapa mítica, inferior e pré-científica do conhecimento humano (CASTRO-GÓMEZ; GROSFOGUEL, 2007; QUIJANO, 1992).

O programa teórico do grupo $M C$ destaca também, em sua concepção de modernidade, a ideia de exterioridade, que permite pensar os outros mundos (formas de pensar, fazer e ser), que resistiram e seguem resistindo ao projeto moderno. Assim, considera a força epistemológica das histórias locais para pensar a teoria a partir das práxis dos grupos oprimidos.

Escobar (2003) afirma que, nesse sentido, a proposta se aproxima do que Boaventura de Sousa Santos (2010) expõe como Epistemologias do Sul, uma abordagem que provém de uma crítica à epistemologia dominante e concebe a necessidade de uma epistemologia (ou epistemologias), que considere a diversidade de saberes existentes no mundo e os modos de conhecer, especialmente dos povos do Sul. Esse não é 
necessariamente o Sul geográfico, mas uma ideia de Sul global, que abrange os povos historicamente oprimidos pela sociedade colonizadora capitalista. É sob essa ótica que trabalharemos as dimensões da colonialidade e da decolonialidade para revelar como os Krenak compreendem o rompimento da barragem da Samarco e a contaminação do rio Doce.

\section{O projeto moderno-colonial e os Krenak}

O projeto da sociedade moderna-colonial, desde o século XIV, tem avançado sobre os territórios dos povos originários do Brasil. Além do extermínio, esses povos sofreram e sofrem com a invasão de suas terras e territórios, exploração da sua força de trabalho e com a subjugação de suas culturas. Os Krenak, povo que habita as margens do rio Doce, conhecido também como os Borun do Watu (o povo do Watu), enfrentaram e seguem enfrentando violações de seus direitos em função do modelo de desenvolvimento imposto.

O nome Krenak é constituído por dois termos: um é a primeira partícula, kre, que significa cabeça, a outra nak, significa terra. Krenak é a herança que recebemos dos nossos antepassados, das nossas memórias de origem, que nos identifica como "cabeça da terra", como uma humanidade que não consegue se conceber sem essa conexão, sem essa profunda comunhão com a terra. (KRENAK, 2019, p. 48, grifos do autor)

Os Krenak compõem um grupo maior de indígenas que, durante a colonização portuguesa, foram pejorativamente chamados de Botocudos. O termo se referia a diversos grupos étnicos5, caracterizados como índios bravos (PARAísO, 1992) e que utilizavam botoques como adornos labiais ou auriculares.

Esses grupos indígenas recolheram-se no vale do rio Doce na tentativa de resistência pela invisibilidade, mas com o avanço colonial, após o declínio do ciclo do

\footnotetext{
${ }^{5}$ Botocudos era a nomenclatura genérica utilizada pelos colonizadores para se referirem a diversos grupos étnicos: Aknenuk, Etwet, Nep-nep, Nakrehé, Takruk-krak, Gutkrak, Nakshapmã, Krenak, Mifiajirum, Jiporok, Minajjirum, Pojixá, Naknenuk, Krakmun, Pejaerum. Também eram chamados de Aimorés ou Tapuias e pertencem ao tronco linguístico Macro-Jê (PARAísO, 1992, p. 419-420).
} 
ouro, no século XVIII, a Mata Atlântica do vale do rio Doce começou a ser explorada para as atividades da agricultura extensiva, comércio e pecuária. Ocorreu a instalação de colonos e aldeamentos indígenas para a dominação e exploração da sua mão de obra e foram montados quartéis e presídios, para fazerem frente à resistência indígena. Em 1808, a Declaração de Guerra de Extermínio por parte do Rei Dom João VI a esses grupos étnicos, justificada pela necessidade de civilizar o país, deu início ao genocídio em massa dos botocudos (PARAíso, 1992, p. 417-423).

No começo do século XX, outra investida violenta contra o território indígena foi a construção da estrada de ferro Vitória-Minas - para os Krenak, Guapok, o caminho de ferro, da Companhia Siderúrgica Vale do Rio Doce ${ }^{6}$, que avançou sobre os últimos redutos dos territórios desses povos. Esse período foi influenciado pela onda positivista que se fortalecia no Brasil, especialmente nas escolas militares. Sob o lema de "ordem e progresso", novas instituições foram criadas para subsidiar o ingresso do país no processo de desenvolvimento que estava em curso. É o caso do Serviço de Proteção aos Índios e Localização dos Trabalhadores Nacionais (SPILTN), criado em 1910 pelo Marechal Rondon, no intuito de promover o processo civilizatório dos índios. Segundo a perspectiva do órgão, os indígenas necessitavam ser tutelados pelo Estado até que fossem progressivamente civilizados e inseridos na sociedade. As relações do órgão com os indígenas eram, portanto, contraditórias e conflituosas (BARRETO; EITERER, 2015).

Em 1918, o SPILTN, que a partir desse ano, mudou sua nomenclatura para Serviço de Proteção aos Índios (SPI), negociou junto ao Estado uma área de reserva para os Krenak, que, já em 1921, começou a ser alvo de arrendamento pelo próprio SPI para trabalhadores que estavam chegando à região. Em 1955, com a descoberta de uma mina de mica dentro da reserva indígena, houve uma pressão muito grande da sociedade para a retomada das terras pelo Estado (PARAÍsO, 1992). Os Krenak foram, então, transferidos para uma área da etnia Maxacali no Norte do estado, em 1957, onde vivenciaram conflitos, fome e doenças. Em 1959, voltaram a pé para o rio Doce, onde ficaram sem

\footnotetext{
${ }^{6}$ Naquela época, a empresa era estatal. Hoje é uma multinacional, responsável, junto com as mineradoras Samarco e a australiana BHP Billiton, pelo rompimento da barragem de rejeitos que atingiu o rio Doce em 2015 .
} 
assistência, até serem enviados para um posto indígena no estado de São Paulo (PARAÍSO, 1992).

O SPI, extinto em 1967, sob acusações de corrupção e maus tratos aos indígenas, foi substituído pela Fundação Nacional do Índio (FUNAI). Em 1969, já no período da ditadura militar, foi criado, na área Krenak, em Resplendor/MG, o Reformatório Agrícola Indígena, o qual, na realidade, funcionava como um presídio que reunia todos os índios considerados desordeiros, que eram submetidos a trabalhos forçados e castigos (FIOROTT, 2017).

Em 1971, os Krenak foram transferidos para a Fazenda Guarani, em Carmésia/MG, onde ficaram por cerca de dez anos. Em 1980, após a enchente de 1979, conseguiram, enfim, retornar a pé para sua região de origem, no Vale do Rio Doce, onde estão até hoje na reserva conquistada: a Terra Indígena Krenak, localizada entre as cidades de Resplendor e Conselheiro Pena, à margem esquerda do rio Doce (PARAíSO, 1992). A atual Terra Indígena Krenak possui 4.039,82 (quatro mil e trinta e nove hectares e oitenta e dois ares), conforme Decreto Federal de homologação no ano de 2001, onde vivem cerca de 430 pessoas, em diversas aldeias como: Uatu, Nakrerré, Atorãn, Krenak, Naknenuk Takruk e Borum-Ererré (FIOROTT, 2017).

Os anciões Krenak contam através da oralidade, as histórias que vêm sendo passadas de geração a geração, sobre os tempos da guerra declarada em 1808 e todos os conflitos posteriores, como mostra o trecho a seguir, extraído do livro "Borun do Watu", produzido a pedido dos próprios indígenas no intuito de divulgar sua história de forma escrita e contrapor as versões dos colonizadores. O livro foi publicado em 1992, pelo Centro de Documentação Eloy Ferreira da Silva (CEDEFES):

E vimos o cerco apertar. Nossos muitos olhos viam surgir por toda a parte os quartéis no Watu, no Jequitinhonha, no Krikaré, no Arakuá. Grupos saíam para nos atacar. O cano de suas armas nos miravam. Ao relâmpago que elas vomitavam caíam muitos mortos. E víamos que a guerra ia ser muito violenta. MESMO ASSIM NOS ORGANIZAMOS E RESISTIMOS! [...] Muitos dos nossos se submetiam, se entregavam, cansados de resistir, loucos para continuar vivos e sofrendo menos. E era triste vê-los nos quartéis subjugados. Não. Já não eram mais BORUN, nem 
eram Kraí! [...]. O chefe branco Marliere, e seus ajudantes trazem presentes, falam da amizade. E diz que os Kraí devem parar com os ataques. Mas já sabíamos que a PAZ DELES era para ficar sem problemas com nossas terras! E ajudar a chegar GUAPOK, o caminho de ferro! (SOARES, 1992, p. 56-64, grifo da autora)

As narrativas compartilhadas no tempo presente, através de publicações que recolheram e relatam as histórias do tempo passado, demonstram a dimensão de sofrimento imposta aos Krenak, entre serem "pacificados"7 ou exterminados, e relembra aos mais jovens as violências físicas e simbólicas sofridas pelos seus anciões.

Esse histórico de extermínios, deslocamentos forçados, roubo de terras, exploração de mão de obra, aldeamentos e pacificação, mostra a dimensão da colonialidade no processo de formação da nação brasileira moderna e seu almejado desenvolvimento, no qual os povos indígenas foram sempre vistos como um empecilho, o qual, às vezes, foi necessário exterminar fisicamente; outras, subjugar moral e culturalmente.

Em 2015, o rompimento da barragem de rejeitos de Fundão provocou mais um drama aos Krenak: a contaminação do rio Doce até a foz, atingindo o cerne da vida dos indígenas. Foi, então, criada uma fundação de direito privado e sem fins lucrativos, a Fundação Renova, através de um Termo de Transação e de Ajustamento de Conduta (TTAC), assinado como acordo extrajudicial entre a União, os governos dos estados de Minas Gerais e do Espírito Santo, as empresas Samarco, Vale S.A. e BHP Billiton do Brasil, com o objetivo de "recuperar, mitigar, remediar, reparar, inclusive indenizar e, nos casos em que não houver possibilidade de reparação, compensar os impactos nos âmbitos socioambiental e socioeconômicos, decorrentes do EVENTO" (TTAC, 2016, p. 7).

A criação da Fundação Renova foi questionada por atingidos, entidades e movimentos sociais, pois o processo que resultou no acordo não contou com a participação das populações atingidas, além de ter constituído, como gestora dos

\footnotetext{
7 A expressão "pacificação" é um termo dos colonizadores, de teor ideológico, porém, ainda recorrente na literatura, para referir-se ao violento processo de dominação dos indígenas derrotados nas batalhas ou capturados e a sua consequente adaptação ou resignação forçada aos costumes e práticas do modo de viver dos brancos, um processo normalmente também mantido por opressões, humilhações e violências diversas.
} 
programas, uma fundação gerenciada pelas próprias empresas causadoras dos danos, e dotada de autonomia. O Acordo chegou a ser suspenso a pedido do Ministério Público Federal (MPF), porém, após negociações, o TTAC e a Fundação Renova prosseguiram como referências para a reparação e compensação, numa relação de poder extremamente assimétrica em relação aos atingidos (VIEIRA; SILVA, 2019).

Diante desse contexto, para compreender o que significou para o povo Krenak, a perda do rio Doce/Watu, faz-se importante o entendimento sobre os sentidos atribuídos ao rio e as relações materiais e espirituais que o povo tem com ele, dimensões que apontam tanto para a insuficiência das ações de reparação empreendidas pela Fundação Renova, quanto para a necessidade de transformações no modelo de desenvolvimento imposto.

\section{Narrativas sobre os sentidos do rio Doce - o Watu}

Para os Krenak, a contaminação do rio Doce foi a morte do Watu. Para compreender os sentidos do rio para esse povo, é necessário compreender que as ideias de natureza se constituem de maneira diferente nas diversas culturas (DESCOLA, 1997). Nessa perspectiva, podemos falar, não em "uma natureza”, mas em "naturezas". Para os $\mathrm{Krenak}^{8}$, o rio Doce, o qual chamam de Watu, não é somente um rio em seu aspecto material, é considerado um ser, uma entidade espiritual, ao qual se referem como pai e mãe de seu povo. O relato de Itamar Krenak, em encontro temático sobre a "Cultura Indígena Krenak", promovido em ambiente remoto, expressa esse entendimento:

O rio Watu é nosso pai e nossa mãe, porque dele a gente sempre fez parte [...] é como um sangue nosso, que corre na nossa veia. O povo nosso tá abalado, de maneira que é um desafio muito grande pra poder caminhar [...] com essa perda, foi embora com ele parte da nossa vida

\footnotetext{
${ }^{8} \mathrm{Na}$ TI Krenak existem seis aldeias diferentes, com peculiaridades e diferenças entre si, portanto, pode haver nuances diferentes e até conflitos internos em relação à percepção sobre o desastre e os caminhos para reparação. Focamos, no presente trabalho, nos pontos convergentes das expressões dos diversos grupos que foram tornadas públicas.
} 
cultural, a história nossa de caçar, de fazer religião, de batizar nossas crianças. (CULTURA..., 2020, informação verbal) ${ }^{9}$

A identidade Krenak é profundamente construída em relação ao rio, pois se autodenominam os "Borun do Watu”, o povo do rio Watu. Logo, perder o Watu, é perder parte de si. Segundo Itamar, jovem liderança Krenak, professor, especializado em Educação Indígena pela Faculdade de Educação da Universidade Federal de Minas Gerais, seu filho de dois anos não teve a oportunidade de ser batizado nas águas do rio, nem seus primeiros passos foram dados no Watu, pois, atualmente, ainda estão impedidos de se aproximar do rio, que se encontra cercado em função dos riscos de contaminação. $O$ batismo no Watu é considerado um ritual de bênção, purificação e proteção, para que as crianças cresçam com boa saúde.

Um outro sentido importante atribuído ao rio pelo povo Krenak diz respeito à imagem de protetor. Acreditam que o Watu agiu em defesa de seu povo na enchente de 1979, período em que estavam exilados em outras terras. A enchente tirou os brancos do território Krenak e teria sido um sinal para que os indígenas pudessem regressar. Itamar Krenak relata que nasceu quando sua mãe, Dejanira, voltava a pé, tendo caminhado mais de seis meses junto com outros parentes para retornar às margens do rio Doce:

Aí aconteceu uma coisa muito importante, que foi a enchente de 79, e isso ficou na nossa história, na memória, porque o Watu avisa que tá na hora de voltar pra casa. Então, nesse dia a enchente veio e arrancou, tirou os kraí kreton da nossa terra, tirou todo mundo, levou tudo. E nesse momento o povo nosso entrou e tá até hoje. (CULTURA..., 2020, informação verbal $)^{10}$

A contaminação do rio promoveu perdas existenciais que vão desde a reprodução da vida material ao sentido da existência como ser indígena Krenak. Quando aquele a

\footnotetext{
9 Informação fornecida por Itamar Krenak em 23 de junho de 2020, na transmissão ao vivo do canal NAGÔ UFJF-GV: <https://www.youtube.com/watch?v=LGyY1T2xT2A\&t=2436s>.

${ }^{10}$ Informação fornecida por Itamar Krenak em 23 de junho de 2020, na transmissão ao vivo do canal NAGÔ UFJF-GV: <https://www.youtube.com/watch?v=LGyY1T2xT2A\&t=2436s $>$.
} 
quem atribuem sacralidade, reverência e o papel de protetor é atingido, veem-se, também, vulnerabilizados espiritualmente.

Dejanira Krenak, mãe de Itamar, conta sobre os impactos da perda do Watu em relação à religiosidade e à alimentação.

Eu dou aula de cultura, né, eu não sei ler, mas a minha leitura tá na minha cabeça, na minha inteligência de manter a cultura [...] a gente fica, assim, ajudando, fala da religião, do nosso Parque do Rio Doce que a gente perdeu também, então a gente fica assim muito sentido, que a gente faz parte da religião, religião da água a gente perdeu, a gente perdeu todo nosso alimento que é o peixe que a gente alimentava, isso foi muito triste pra todos nós. Até hoje eu fico muito triste. Aí eu vou me entreter na beira da fogueira, eu canto. Nós perdemos nosso rio Doce, foi muito doído, viu. A gente não é de hoje vem sofrendo. Mas nós não perdemos a luta e nem a guerra. A gente vai em frente. (CULTURA..., 2020, informação verbal) ${ }^{11}$

A narrativa de Dejanira associa o sofrimento decorrente da contaminação do rio Doce ao sofrimento histórico e ressalta a tristeza ocasionada pelas perdas. Ela relata, também, a força encontrada na cultura: na língua, na fogueira, no canto, no processo de ensinar, de transmitir os valores ancestrais de sua cultura às novas gerações. Além de compartilhar seus saberes nos espaços cotidianos, ela ensina na escola indígena dentro da aldeia. É também nos marét, espíritos ancestrais, que os Krenak afirmam encontrar proteção, força e refúgio.

Em outro relato, Dejanira narrou o impacto da contaminação do rio sobre as medicinas tradicionais, tanto em função da morte dos peixes, quanto das ervas que nasciam às margens e não são mais encontradas:

A Curvina serve pra remédio, ela tem uma pedra na cabeça, e aquela pedra serve pra remédio pra gente, pra dor de bexiga, a gente cozinha ela e bebe, e serve pra remédio. Serve pra quando está com dor por dentro, é um antibiótico. A gente sempre guarda as pedras dos peixes.

\footnotetext{
${ }^{11}$ Informação fornecida por Dejanira Krenak em 23 de junho de 2020, na transmissão ao vivo do canal NAGÔ UFJF-GV: <https://www.youtube.com/watch?v=LGyY1T2xT2A\&t=2436s>.
} 
Hoje a gente não tem mais. A gente conhece vários remédios da beira do rio, mas agora a gente não acha mais nada, morreu! (KRENAK, D., 2016, informação verbal, apud FIOROTT, 2017, p. 124)

Os relatos comprovam como o desastre no rio Doce tem acarretado uma profunda desagregação nas tramas materiais e simbólicas da vida coletiva do povo Krenak. Quanto ao sustento diário das famílias, o grupo passou a ser dependente do mercado externo, em esferas em que possuíam autonomia, como o acesso ao peixe, uma das bases alimentares dos indígenas; ou à caça, já que muitos animais do entorno morreram ou estão doentes. Assim, hábitos alimentares estão sendo modificados. O mesmo ocorre com o consumo de água, na medida em que, até o presente momento, no ano de 2020, cinco anos após o rompimento da barragem, a comunidade continua dependendo do suprimento mensal de água mineral recebida de vias externas, uma das medidas compensatórias implementadas pela Fundação Renova.

De acordo com os relatórios mensais disponíveis na página da Fundação Renova, no período de 21/10/2020 a 20/11/2020, os povos indígenas de Resplendor receberam cinco litros de água mineral, por pessoa, por dia, totalizando 90.000 litros (FUNDAÇÃO RENOVA, 2021). A criação de gado, outra atividade basilar da economia do grupo, também foi gravemente prejudicada e ainda depende de insumos externos, como ração, silagem e sal mineral para bovinos. No mesmo período citado, foram entregues 300 sacos de $25 \mathrm{~kg}$ de sal e 240 toneladas de silagem de milho para 100 famílias. Ainda no mês citado, o valor da indenização destinado a cada uma das 137 famílias foi de $\mathrm{R} \$$ 9.405,00 (FUNDAÇÃO RENOVA, 2021). Logo após o desastre, as reivindicações imediatas dos Krenak, expressas em uma carta aberta datada de 16 de novembro de 2015, foram: suprimento de água para beber e para necessidades diversas; manutenção do gado Krenak; retirada imediata do gado da aldeia, devido ao uso das margens para dessedentação. Além disso, exigiram projetos voltados para caça, pesca, plantação e indenização por danos morais causados à cultura e à religião em torno do Watu (FIOROTT, 2017, p. 147). 
No que diz respeito à medicina tradicional praticada pelo grupo, a ausência das plantas e dos peixes utilizados e obtidos nas águas e matas ciliares compromete tanto as bases da vida material ligadas à saúde do corpo, quanto as teias simbólicas do sistema de cura ancestral. Alguns saberes e práticas tradicionais dos anciões estão suspensos por tempo indeterminado, recolhendo-se à dimensão da memória, e esses ficam, em parte, impedidos de exercer seus papéis como portadores de conhecimentos e mediadores da cura.

Com a falta dos remédios tradicionais, o grupo passa a depender dos medicamentos da farmácia, e, portanto, necessitam ir mais à cidade. A cada saída do território, ficam suscetíveis a outras doenças. A necessidade recorrente dos suprimentos, trazidos por pessoas de fora do território ou buscados por eles na cidade, afeta os espaços e os ritmos do grupo. Já na dimensão da sociabilidade, o grupo foi atingido na medida em que foram privados de diversos momentos de interação social que se davam em torno do rio, como nadar, pescar, assar e partilhar o peixe à beira-rio, brincar nas águas, passear nas ilhas, algumas delas consideradas sagradas.

Formas de agir e fazer a reprodução da vida, costumes rotineiros e também dos tempos extraordinários, dos momentos cerimoniais e de festa, estão sendo transformados em função de uma nova dinâmica imposta pelo violento desastre. De acordo com Fiorott (2017), as pessoas têm buscado a sociabilidade e o lazer fora do território, nas cidades, e têm surgido casos de depressão e aumento do alcoolismo. No campo da religiosidade, os Krenak estão privados de exercerem os ritos do batismo, os rituais da lua cheia à beira-rio e outras atividades religiosas ligadas ao Watu, o que também afeta os laços de sociabilidade e valores que se estabelecem.

O rio faz parte do ser Krenak, e a contaminação de suas águas promove modificações no cotidiano, que abarcam desde aquilo que se come, àquilo que se utiliza para cura, que se comemora e celebra, até o que se percebe e se sente. 


\section{Colonialidade, decolonialidade e resistência}

Os depoimentos analisados de indígenas Krenak, além de enfatizarem os sentidos do Watu para o povo e as consequências de sua perda, em vários momentos remetem aos tempos da colonização e à dimensão da colonialidade. Confluem para uma compreensão de que o ocorrido consiste em mais uma violência articulada, guiada por interesses econômicos e políticos hegemônicos, e que há séculos tem atingido o povo Krenak, sustentados por uma dominação baseada na ideia de raça, na inferiorização e negação da diferença, como expressa o trecho a seguir, do livro "Ideias para adiar o fim do mundo", de Ailton Krenak:

O que está na base da história do nosso país, que continua a ser incapaz de acolher os seus habitantes originais - sempre recorrendo a políticas desumanas para promover mudanças em formas de vida que essas populações conseguiram manter por muito tempo, mesmo sob o ataque feroz das forças coloniais, que até hoje sobrevivem na mentalidade cotidiana de muitos brasileiros -, é a ideia de que os índios deveriam estar contribuindo para o sucesso de um projeto de exaustão da natureza. $O$ Watu, esse rio que sustentou a nossa vida às margens do rio Doce, entre Minas Gerais e o Espírito Santo, numa extensão de seiscentos quilômetros, está todo coberto de um material tóxico que desceu de uma barragem de contenção de resíduos, o que nos deixou órfãos e acompanhando o rio em coma. (KRENAK, 2019, p. 42)

As narrativas construídas sobre o desastre evocam as memórias da declaração de guerra de extermínio em 1808, a expropriação de seu território ancestral, as duas remoções forçadas ou exílios, as prisões no presídio ideologicamente intitulado “reformatório Krenak", a morte do Watu, e, recentemente, a vulnerabilidade à qual estão expostos diante do descaso do governo com as populações indígenas em relação às suas necessidades $^{12}$. Na leitura do desastre, não como um fato isolado, e sim articulado a esse

\footnotetext{
${ }^{12}$ No ano de 2020, a OMS declarou Pandemia de COVID-19 no mundo. Não é objetivo do artigo uma discussão sobre a pandemia, entretanto, cabe registrar que ela atinge de forma peculiar os povos indígenas, já que muitas etnias vivem em grupo doméstico que abriga vários grupos familiares, o que facilita o contágio pela COVID-19; estão normalmente afastados dos centros de tratamento médico ou localizados em regiões com recursos médicos limitados; e, também, em função de a pandemia atingir de forma mais intensa os idosos, que, para os povos indígenas, normalmente são suas lideranças religiosas e políticas.
} 
histórico de violências, Douglas Krenak, fala em uma guerra sem fim, articulada a uma resistência sem fim.

A história do nosso povo é uma história muito violenta nessa questão da imposição cultural e durante o período não só da ditadura, mas o período colonial, o povo foi forçado a assimilar uma outra cultura [...]. Muitas vidas tiveram que ser ceifadas, pra que hoje eu estivesse aqui falando da cultura do meu povo, da história de luta do meu povo, dessa guerra sem fim que assola a todos nós principalmente meu povo Krenak [...]. Mesmo hoje sofrendo com a morte do nosso sagrado Watu, do nosso grande pai protetor, nós ainda buscamos força espiritual, com outras conexões, mas o que a gente tem que lembrar é que o que estão fazendo, estão matando nosso povo aos poucos [...]. Nós teremos também uma resistência sem fim. (POVO..., 2020, informação verbal) ${ }^{13}$

É em função dessa leitura de perpetuação de um projeto colonial que se metamorfoseia em diversas faces (catequização/salvação, civilização, progresso, desenvolvimento) que a dimensão da colonialidade emerge como categoria que auxilia a compreender essa realidade.

A despeito dos projetos realizados em prol da reparação dos danos, impostos às empresas mineradoras por meio do Termo de Transação e de Ajustamento de Conduta (TTAC), os Krenak, assim como muitos outros grupos atingidos, consideram que os danos são irreparáveis. Sempre haverá algo que não se pode reparar, que foi perdido, violado, marcado para sempre, como declara Wakrewa, jovem da Terra Indígena Krenak, a respeito do Watu: "Nunca vai voltar o que era. Os remédios, a capivara, não é só isso, é a cultura de um povo e é muito mais do que a gente pode imaginar [...] não existe valor que paga o que nós perdemos" (A PROTEÇÃO..., 2020, informação verbal). Em outra passagem, ela descreve:

Nós não temos nenhum tipo de diálogo com a Renova [...] tio Euclides tinha 106 anos, viveu muito, um livro vivo durante muito tempo, o qual as páginas desse livro nós não podemos mais ler porque esse livro foi

\footnotetext{
13 Informação fornecida por Douglas Krenak em 14 de maio de 2020, na transmissão ao vivo do canal NAGÔ UFJF-GV: $\langle$ https://www.youtube.com/watch?v=M2DYt7BB_s4>.
} 
fechado e a pior forma que foi fechado foi após o crime de 2015, porque no seu leito de morte ele pediu pra comer o bó, o peixe do Watu. Ali seus sobrinhos, sua irmã, com ele no leito de morte, ele dizia que queria, mas nós não podíamos dar pra ele, aí ele dizia, então era pra cantar e ele fez ainda em vida um canto pra nós que é muito importante. (A PROTEÇÃO..., 2020, informação verbal) $)^{14}$

Os processos de reparação em curso, por meio da Fundação Renova, revelam ainda impasses e conflitos entre racionalidades e culturas distintas. Por exemplo, os Krenak relatam a proposta de construção de poços para criarem peixes, sendo que não faz parte de sua cultura criar animais presos. Além disso, existem pressões para elaboração de projetos com prazos que não respeitam as temporalidades do lugar e da cultura ou o momento de vulnerabilidade emocional em que se encontram para se envolverem em atividades que demandam muito tempo e dedicação, como a elaboração dos projetos, constantes reuniões, avaliações de processos, pressões por quantificação de aspectos que são difíceis de serem pensados em termos quantitativos, como relata Douglas Krenak (2020):

E as empresas a todo momento, junto com os órgãos competentes, impondo para nossa comunidade que a gente tem que dar uma resposta rápido. Se você não tem um rio, eles têm que construir um tanque de peixes né. Assim, é fácil, eles te tiram um rio, o peixe que você pescava no rio, e te dão um tanque de peixe. (POVO..., 2020, informação verbal) ${ }^{15}$

O povo pede cuidados com suas subjetividades e temporalidades, necessitam de cura nas dimensões afetivas e espirituais que foram abaladas. São necessidades que não se resolvem simplesmente numa lógica técnica e institucional, com projetos, apoio psicológico e assistência social (ainda que esses sejam importantes), pois representam rupturas profundas que precisam ser gestadas a partir da própria lógica cultural e das suas pedagogias de resistir.

\footnotetext{
14 Informação fornecida por Wakrewa Krenak em 22 de julho de 2020, na transmissão ao vivo do canal NAGÔ UFJF-GV: <https://www.youtube.com/watch?v=E-VV1CdZmxs>.

15 Informação fornecida por Douglas Krenak em 14 de maio de 2020, na transmissão ao vivo do canal NAGÔ UFJF-GV: <https://www.youtube.com/watch?v=M2DYt7BB_s4>.
} 


\subsection{A retomada do território de Sete Salões}

Com a contaminação do sagrado Watu, os Krenak têm reforçado a luta por demarcação de uma outra porção de seu território, da qual foram expropriados e que, posteriormente, como uma compensação de impactos ambientais, foi transformada no Parque Estadual de Sete Salões, de forma sobreposta ao seu território ancestral.

A retomada desse território tem sido vista como fundamental no momento, por ser um local onde existem águas puras, plantas medicinais, sementes e outros elementos da natureza para a confecção de artesanato. Além disso, possibilitaria espaço para as novas gerações, já que a população vem aumentando, e sua retomada traria um significativo aporte em termos de força espiritual e ânimo para o povo, pois as montanhas e grutas de Sete Salões são lugares sagrados, considerados morada de espíritos ancestrais, como relata Itamar Krenak:

Num período que nosso povo foi muito perseguido e maltratado pelos colonos, pela invasão territorial, teve uma época que nosso povo, ele se escondeu dentro das grutas de Sete Salões. Sete Salões existe umas grutas lá que cabem mais de 300 pessoas e é um lugar muito importante, sagrado, ele é forte, por ter segurado a vida de nosso povo [...] e a importância dessas grutas altas, é que nossos marét também habitam nessa região né. É uma região onde a gente tem força, a gente busca esse fortalecimento. E hoje nessa região ainda existe imbira, existe o cipó imbé, existe as plantas medicinais que é feito os remédios nossos, que é feito a flecha, o tecido da flecha que é feito da imbira, [...] os colares, que a gente pode estar coletando e é um lugar onde tem água em abundância. (CULTURA..., 2020, informação verbal) ${ }^{16}$

Os usos e percepções da natureza revelam outras matrizes que diferem da tradicional racionalidade ocidental e apontam para outros mundos possíveis. O território Krenak é cosmografado e apresenta vínculos de continuidade entre o mundo biofísico, o humano e o supranatural. O rio, as montanhas altas, algumas grutas e ilhas são considerados sagrados para o povo Krenak. Os seres vivos e não vivos, e, com frequência supranaturais, não são vistos como entes que constituem domínios distintos e separados.

\footnotetext{
${ }^{16}$ Informação fornecida por Itamar Krenak em 23 de junho de 2020, na transmissão ao vivo do canal NAGÔ UFJF-GV: <https://www.youtube.com/watch?v=LGyY1T2xT2A\&t=2436s >.
} 
A continuidade e o relacionamento entre esses três mundos estão culturalmente arraigados através de símbolos, rituais e práticas, que, mediados por relações sociais, constituem uma territorialidade própria do lugar (ESCOBAR, 2005; LITTLE, 2002). Portanto, a retomada do território de Sete Salões envolve dimensões materiais e imateriais fundamentais para a cultura.

O Relatório Circunstanciado de Identificação e Delimitação (RCID) de Sete Salões primeira etapa do processo de regularização de terra indígena - foi elaborado pela FUNAI no ano de 2017, porém, não avançou em função do contexto político de retrocessos, desmontes e ataques aos direitos territoriais dos povos indígenas (FIOROTT, 2017). Cabe lembrar que uma decisão contra o marco temporal no julgamento do Recurso Extraordinário n. 1.017 .365 , conhecido como “caso Xokleng”, de repercussão geral reconhecida ${ }^{17}$, poderá servir como parâmetro para a demarcação das terras indígenas, influenciando positivamente o processo de retomada do território de Sete Salóes pelos Krenak.

\subsection{As pedagogias de resistir}

Além da reivindicação pela demarcação do território de Sete Salões por parte de lideranças mencionadas, outro aspecto que se destaca nos depoimentos, é uma crítica profunda ao modelo de sociedade vigente. Essa crítica tem como alvos mais recorrentes: o modo de produção e desenvolvimento capitalista, que prioriza o lucro, em detrimento das vidas humanas e não humanas; a dicotomia entre sociedade e natureza, que considera a natureza como mero recurso para finalidades utilitárias; a narrativa colonial de superioridade da cultura branca europeia e a subjugação das outras culturas; e a crise dos valores éticos, na medida em que o materialismo se sobrepõe à busca do autoconhecimento, da espiritualidade e da sabedoria.

\footnotetext{
17 A repercussão geral do caso foi reconhecida pelo Supremo Tribunal Federal em fevereiro de 2019, logo, o que for julgado para esse caso valerá para todos os demais que envolvam demarcação de terras indígenas. Mais informações disponíveis em: APIB - Articulação dos Povos Indigenas do Brasil. O futuro das terras indígenas nas mãos do STF. [S.I.], 19 out. 2020. Disponível em: <https://apiboficial.org/2020/10/19/0futuro-das-terras-indigenas-nas-maos-do-stf/>. Acesso em: 4 mar. 2021.
} 
Douglas Krenak, em depoimento ao professor Reinaldo Duque, sobre a história de luta e resistência Krenak nos 212 anos após a Carta Régia, critica a prevalência do “ter” sobre o "ser" e o modo capitalista corporificado nas empresas mineradoras em sua forma de operar e lidar com os danos causados.

Eu acho que o que tem acontecido as pessoas estão se distanciando da sua origem, do que realmente elas são, então, hoje têm sentimento por muitas coisas materiais, ao invés de sentimento de respeito pelo próprio ser humano, então isso influi muito. A gente tem passado por muitos problemas aqui no estado de Minas, por exemplo, em que grandes empresas de mineração destroem vidas, meio ambiente, e isso se resolve com a mera indenização [...]. Eu acho que muito vem desse sentimento selvagem de capitalismo selvagem, destruidor [...]. Busquem respeitar mais um pouco a mãe natureza, o meio ambiente, entendam que isso não é conversa de índio, isso é sabedoria. (POVO..., 2020, informação verbal $)^{18}$

Sua expressão “conversa de índio", revela o preconceito e a desvalorização com a qual os indígenas foram e ainda são estigmatizados na sociedade brasileira. Ele destaca também a importância de valores como o respeito e a sabedoria. Já no relato de Wakrewa Krenak, ela contrasta a riqueza material, alvo da ganância dos grandes projetos mineradores, com a riqueza cultural e espiritual que sustenta o povo.

A mineração é morte pra humanidade. Porque quando a mineração chega, chega também o ódio, chega a ganância e chega aquele espírito que quer se apossar de tudo e levar toda nossa riqueza. A riqueza material né, que são as riquezas que contém na nossa terra. Porque a riqueza que existe dentro de nós indígenas, se chama cultura e essa a mineração não mata. (A PROTEÇÃO..., 2020, informação verbal) ${ }^{19}$

A compreensão de Wakrewa revela que os megaempreendimentos minerários, ao contrário do que ideologicamente anunciam, não representam, para os povos indígenas,

\footnotetext{
18 Informação fornecida por Douglas Krenak em 14 de maio de 2020, na transmissão ao vivo do canal NAGÔ UFJF-GV: <https://www.youtube.com/watch?v=M2DYt7BB_s4>.

19 Informação fornecida por Wakrewa Krenak em 22 de julho de 2020, na transmissão ao vivo do canal NAGÔ UFJF-GV: <https://www.youtube.com/watch?v=E-VV1CdZmxs>.
} 
desenvolvimentos, melhorias e esperanças para a produção e reprodução de suas vidas e dos outros seres não humanos com os quais coexistem.

O escritor, ambientalista e importante liderança indígena Ailton Krenak, que teve participação fundamental no processo de garantia dos direitos indígenas na Constituição de 1988, tem se destacado na esfera pública como uma voz potente da crítica ao pensamento moderno-colonial em suas ações, palestras e livros. Ailton Krenak (2019) tem denunciado a criação estrutural da pobreza pela modernização, o genocídio dos povos originários, os problemas provocados pela separação entre homem e natureza e as ideias modernas de desenvolvimento.

As bases das críticas ao projeto moderno-colonial que elencamos anteriormente são, ao mesmo tempo, evocações de outras realidades possíveis, que, a partir do reconhecimento da ferida colonial e da colonialidade, apontam para processos decoloniais. Outras etnias, cada vez mais presentes na esfera pública brasileira (na política, na academia, na literatura indígena), num processo que vem se intensificando desde as mobilizações e conquistas da constituição de 1988, também têm erguido suas vozes em defesa dessas outras formas de ver o mundo e de viver.

É possível interpretar essas vozes como portadoras de um pensamento originário que atua também como um pensamento de fronteira, o qual, segundo Mignolo (2007), se forma a partir da ferida colonial e expressa o conhecimento concebido desde as fronteiras do sistema mundo moderno-colonial, que transita entre mundos diferentes e é capaz de funcionar em uma outra lógica, outros imaginários. Esse tem sido um importante impacto epistêmico-político que os estudos coloniais, pós-coloniais ou decoloniais têm em comum: "se caracterizarem e dinamizarem pelo aparecimento e enraizamento público-político das minorias político-culturais e dos sujeitos de minorias que revelam exatamente o caráter contraditório da colonização" (DANNER et al., 2020, p. 68).

As denúncias e críticas vêm acompanhadas da enunciação de uma resistência ancorada na cultura como força para, diante dos contínuos ataques, reorganizarem o sentido de sua vida na ordem social e simbólica de seu grupo, baseados na dimensão da 
etnicidade. Etnicidade entendida como estratégia de mobilização e expressão políticoorganizacional que reforça as reivindicações étnicas frente ao Estado (CUNHA, 2009).

\section{Considerações finais}

A contaminação das águas do rio Doce modificou profundamente o cotidiano da vida Krenak, do seu lugar de morada ao seu lugar do sagrado. Com a impossibilidade de pescar, nadar, beber a água do rio, fazer seus rituais, acessar ilhas sagradas e retirar do rio remédios para a cura de diversos males, o povo Krenak foi privado, mais uma vez, de viver e ser conforme sua cultura.

Os Krenak elaboram e compreendem o rompimento da barragem e a forma como foram atingidos, como mais um episódio de uma "guerra sem fim", categoria construída a partir da memória oral dos mais antigos e que acionam para atribuir um sentido de inter-relação e continuidade à série de expropriações, violências e diásporas que recaíram sobre seu povo desde os tempos coloniais até o momento presente. Paralelamente, utilizam a categoria de "resistência sem fim", reforçando a identidade Krenak como um povo guerreiro, cuja resistência está ancorada na cultura e em sua íntima conexão com o rio Watu, perspectiva que guarda as raízes do que significa ser “Borun do Watu”.

Reconhecendo o desastre como uma das faces assumidas pelo desenvolvimento da sociedade moderna-colonial ao longo do tempo, suas narrativas convergem para uma crítica profunda a esse projeto. Portanto, diante da contaminação do Watu, diversas lideranças recolocam a centralidade de sua reivindicação pelo território ancestral de Sete Salões, como aspecto fundamental para produção e reprodução da vida, reivindicando o respeito, o reconhecimento de outra forma de viver, conviver e gestar o ambiente. Reivindicam outros modos de existência e de possibilidade de vida em comum. Uma crítica à colonialidade nesse conflito e um movimento rumo à descolonização.

Os Krenak se posicionam nas fronteiras entre o mundo único do projeto moderno, colonial, capitalista, e a diversidade de mundos vividos e anunciados pelos povos originários. Desse lugar, partilham suas cosmologias, saberes e sentimentos. Confrontam a universalidade, o apagamento da diferença e tensionam a epistemologia 
colonial/moderna. Anunciam a possibilidade de outras subjetividades, outros desenvolvimentos, outros mundos possíveis. Um caminho ainda em construção, para o qual não apresentam modelos, já que essa não é uma tendência dos sistemas de pensamento originários.

Consideramos a relevância de desvelar e apresentar outros sentidos provocados pelo desastre do rompimento junto aos povos atingidos, frente a um caso tão grave como foi a morte do rio Doce, o Watu. Episódios de morte e destruição de águas, bichos e gente, que, sem mudanças profundas, tendem a continuar se repetindo de forma estrutural, em tantos outros rios, com tantos outros povos, intensificando sofrimentos históricos. Vamos ouvir o Watu, vamos ouvir os Krenak.

\section{Referências}

A PROTEÇÃO das crianças Krenak diante da mineração - (parte 1). Com a participação de Reinaldo Duque e Wakrewa Krenak. [Governador Valadares: s.n.], 22 jul. 2020. 1 vídeo (59 min.). Publicado pelo canal NAGÔ UFJF-GV. Disponível em:

https://www.youtube.com/watch?v=E-VV1CdZmxs. Acesso em: 25 out. 2020.

BARDIN, Laurence. Análise de conteúdo. São Paulo: Edições 70, 2016.

BARRETO, Marcos Rodrigues; EITERER, Edylane. Memórias indígenas na ditadura: cárcere e tortura no reformatório Krenak. In: CONGRESSO INTERNACIONAL DE HISTÓRIA, 7., 2015, Maringá. Anais eletrônicos [...]. Maringá: UEM, 2015. Disponível em:

http://www.cih.uem.br/anais/2015/trabalhos/1535.pdf. Acesso em: 2 mar. 2021.

CALVINO, Ítalo. A palavra escrita e a não-escrita. In: FIGUEIREDO, Janaína P. Amado Baptista de; FERREIRA, Marieta de Moraes (org.). Usos e abusos da história oral. Rio de Janeiro: Fundação Getúlio Vargas, 2005.

CASTRO-GÓMEZ, Santiago; GROSFOGUEL, Ramón. Prólogo: giro decolonial, teoría crítica y pensamiento heterárquico. In: CASTRO-GÓMEZ, Santiago; GROSFOGUEL, Ramón (eds.), El giro decolonial: reflexiones para una diversidad epistémica más allá del capitalismo global. Bogotá: lesco-Pensar-Siglo del Hombre Editores, 2007. p. 9-23. 
CULTURA Indígena Krenak (Parte 1). Com a participação de Reinaldo Duque, Itamar Krenak e Dejanira Krenak. [Governador Valadares: s.n.], 23 jun. 2020. 1 vídeo (58 min.). Publicado pelo canal NAGÔ UFJF-GV. Disponível em:

https://www.youtube.com/watch?v=LGyY1T2xT2A\&t=2436s. Acesso em: 25 out. 2020.

CUNHA, Manuela Carneiro da. Etnicidade: da cultura residual mas irredutível. In: CULTURA com Aspas e outros ensaios. São Paulo: Cosac Nayf, 2009. p. 235-244.

DANNER, Leno Francisco; DORRICO, Julie; DANNER, Francisco. Decolonialidade, lugar de fala e voz-práxis estético-literária: reflexões desde a literatura indígena brasileira. ALEA Estudos Neolatinos, Rio de Janeiro, v. 22, n. 1, p. 59-74, jan./abr. 2020. Disponível em: https://www.scielo.br/scielo.php?script=sci_arttext\&pid=S1517106X2020000100059\&tlng=pt. Acesso em: 14 nov. 2020.

DESCOLA, Philippe. Ecologia e cosmologia. In: CASTRO, Edna; PINTON, Florence. (org.). Faces do trópico úmido: conceitos e novas questões sobre desenvolvimento e meio ambiente. Belém: CEJUP: UFPA: NAEA, 1997. Disponível em: http://nupaub.fflch.usp.br/sites/nupaub.fflch.usp.br/files/Ecologia\%20e\%20Cosmologia147. pdf. Acesso em: 28 nov. 2020.

ESCOBAR, Arturo. Mundos y conocimientos de otro modo: el programa de investigación de modernidad/colonialidad Latinoamericano. Tabula Rasa, Bogotá, n. 1, p. 51-86, enero/dic. 2003. Disponível em: http://www.revistatabularasa.org/numero-1/escobar.pdf. Acesso em: 24 out. 2020.

ESCOBAR, Arturo. Lugar da natureza e a natureza do lugar: globalização ou pósdesenvolvimento? In: LANDER, Edgardo (org). A colonialidade do saber: eurocentrismo e ciências sociais - perspectivas latino-americanas. Buenos Aires: CLACSO, 2005. p. 63- 79. (Colección Sur Sur)

FIOROTT, Thiago Henrique. A morte do Uatu: impactos do desastre da Samarco/Vale/BHP sobre a sustentabilidade do povo Krenak. 2017. 158 f. Dissertação (Mestrado em Desenvolvimento Sustentável) - Centro de Desenvolvimento Sustentável, Universidade de Brasília, Brasília, 2017.

FUNDAÇÃO RENOVA. Proteção e recuperação da qualidade de vida dos povos indígenas. Belo Horizonte, [s.n.], 2021. Disponível em:

https://www.fundacaorenova.org/programa/protecao-e-recuperacao-da-qualidade-devida-dos-povos-indigenas/. Acesso em: 4 mar. 2021.

KRENAK, Ailton. Ideias para adiar o fim do mundo. 1. ed. São Paulo: Companhia das Letras, 2019. 
LITTLE, Paul. Territórios sociais e povos tradicionais no Brasil: por uma antropologia da territorialidade. In: REUNIÃO BRASILEIRA DE ANTROPOLOGIA, 23., Gramado, 19 de junho de 2002. Anais eletrônicos [...]. [Brasília: UNB], 2003. Disponível em:

http://www.dan.unb.br/images/pdf/anuario_antropologico/Separatas\%202002-2003/20022003 paullittle.pdf. Acesso em: 20 nov. 2020.

MIGNOLO, Walter D. El pensamiento decolonial: desprendimiento y apertura. Um manifiesto. En: Santiago Castro-Gómez y Ramón Grosfoguel (eds.). El giro decolonial: reflexiones para una diversidad epistémica más allá del capitalismo global. Bogotá: lesco-Pensar-Siglo del Hombre Editores, 2007. p. 25-46.

MILANEZ, Bruno; LOSEKANN, Cristina. (org.) Desastre no Vale do Rio Doce: antecedentes, impactos e ações sobre a destruição. Rio de Janeiro: Folio Digital: Letra e imagem, 2016.

PARAÍSO, Maria Hilda Baqueiro. Os Botocudos e sua trajetória histórica. In: CUNHA, Manuela Carneiro da (org.). História dos Índios no Brasil. 2. ed. São Paulo: Companhia das Letras, 1992. p. 423-430.

PEREIRA DE QUEIROZ, Maria Isaura. Relatos Orais: do indizível ao dizível. In: VON SIMON, Olga Rodrigues de Moraes (org.). Experimentos com História de Vida (ItáliaBrasil). São Paulo: Vértice, 1988. p. 14-43.

POVO Krenak: debate sobre história de luta e resistência 212 anos após a Carta Régia: parte 1. Com a participação de Reinaldo Duque e Douglas Krenak. [Governador Valadares: s.n.], 14 mai. 2020. 1 vídeo (60 min.). Publicado pelo canal NAGÔ UFJF-GV. Disponível em: https://www.youtube.com/watch?v=M2DYt7BB_s4. Acesso em: 25 out. 2020.

QUIJANO, Aníbal. Colonialidad y modernidad-racionalidad. In: BONILLO, Heraclio (comp.). Los conquistados. Bogotá: Tercer Mundo Ediciones: FLACSO, 1992. p. 437449.

SANTOS, Boaventura de Sousa; MENESES, Maria Paula. (org.). Epistemologias do Sul, São Paulo: Editora Cortez, 2010.

SOARES, Geralda Chaves. Os Borun do Watu: os índios do rio Doce. Contagem: Cedefes, 1992.

TTAC. Termo de Transação e de Ajustamento de Conduta. 2 mar. 2016. Dispõe sobre acordo entre o Governo Federal, Governo do Estado de Minas Gerais, Governo do Estado do Espírito Santo e as mineradoras Samarco Mineração S/A, Vale S/A e BHP Billiton Brasil Ltda. Brasília: [s.n.], 2016. Disponível em: https://www.fundacaorenova.org/wp- 
content/uploads/2016/07/ttac-final-assinado-para-encaminhamento-e-uso-geral.pdf. Acesso em: 01 mar. 2021.

VIEIRA, Diovana Renoldi; SILVA, Marta Zorzal. Discursos e assimetrias na reparação dos danos decorrentes do desastre da barragem da Samarco. Revista Psicologia Política [online], São Paulo, v. 19, p. 62-83, 2019. Número especial. Disponível em: http://pepsic.bvsalud.org/scielo.php?script=sci_arttext\&pid=S1519549X2019000400005\&lng=pt\&nrm=iso. Acesso em: 03 abr. 2021.

Recebido em: 30/11/2020 Aprovado em: 26/03/2021

Universidade do Estado de Santa Catarina - UDESC Centro de Ciências Humanas e da Educação - FAED revistapercursos@gmail.com 